\title{
ESPAÇO RURAL E GEOGRAFIA: DIFERENTES ABORDAGENS NA RELAÇÃO CAMPO - CIDADE
}

Celbo Antonio Ramos da Fonseca Rosas ${ }^{16}$

\section{Resumo}

A relação entre o campo e a cidade pode ser expressa de formas diversas na leitura da literatura e da realidade. O objetivo desse artigo, que faz parte das discussões da Tese de doutorado intitulada "A (des)construção da dicotomia rural-urbano no Extremo Noroeste Paulista", direciona a análise da relação entre os espaços rural e urbano no contexto material e principalmente imaterial, na formação das expressões culturais de grupos sociais que vivem na conjunção da relação entre esses dois espaços no processo de formação do espaço através da transformação da natureza, conforme as necessidades e seus costumes culturais. Tais resultados partiram da pesquisa relacionando uma análise de base material e imaterial do espaço, resultando numa construção do espaço rural pelas relações sociais.

Palavras-chave: Relação campo - cidade; mundo rural; construção do espaço.

\section{RURAL SPACE AND GEOGRAPHY: DIFFERENT APPROACHES TO THE COUNTRY-CITY RELATIONSHIP}

\begin{abstract}
The relationship between the country and the city can be expressed in various ways by reading literature and reality. The purpose of this article, which is part of the discussion of the $\mathrm{PhD}$ thesis entitled "The (de)construction of rural-urban dichotomy in the Far Northwest of São Paulo," directs the analysis of the relationship between rural and urban spaces in material and mostly immaterial contexts, in the formation of cultural expressions of social groups living at the bridge of the relationship between these two spaces in the process of space formation via the transformation of nature, according to their needs and cultural customs. These results split from the research connecting an analysis of material and immaterial bases of the space, resulting in the construction of rural space by social relations.
\end{abstract}

Keywords Country-city relationship; rural; construction of space.

\section{Introdução}

O objetivo desse artigo é a construção de uma relação entre o campo e a cidade pelos aspectos materiais e imateriais, destacando a formação do conceito de geografia

\footnotetext{
16 Doutor em Geografia - Docente da Universidade Estadual de Ponta Grossa - UEPG. Departamento de Geociências. Rua Herculano de Freitas, 424, Ap 12, 84015-105, Jd. Carvalho. Ponta Grossa - PR. Fones: (42) 9998-6300 / (42) 3027-4539. E-mail: celboantonio@yahoo.com.br
}

Divers@! Revista Eletrônica Interdisciplinar/Matinhos/Vol.7, n.1, p. /Jan./jun./2014. 


\section{DIVERS(a)}

cultural, que baseará o processo de construção do espaço geográfico pelas sociedades, destacando seu modo de vida e suas necessidades. Diante desse pressuposto, buscou-se analisar a relação campo-cidade no contexto do modo de produção capitalista, que relaciona as necessidades sociais aos modos de consumo impostos pela sociedade consumidora de mercadorias.

Nesse contexto, a geografia cultural, na base complementar do método dialético, é utilizada para analisar uma lacuna geográfica da construção do espaço, que á a base imaterial do conhecimento social, que no contexto da formação de cada sociedade, é relacionada de acordo com cada individualidade, na relação entre o rural e o urbano. As discussões entre o rural e o urbano serviram para demonstrar a relação entre a base material e imaterial da formação e construção do espaço, enfatizando as peculiaridades de cada sociedade.

\section{Construção dos espaços rural e urbano no contexto da materialidade e imaterialidade}

O território, expressão local da relação dialética entre o rural e o urbano possui diversas visões que precisam ser consideradas além do caráter econômico, político e ambiental, e que compõe a expressão desse mundo, que é a cultura local, a identidade dos moradores que vivem e constroem sua vida em comunidades. Nota-se que a expressão da identidade local é muito mais presente e aflorada em comunidades rurais do que em centros urbanos, uma vez que a troca de residências, e o uso da especulação imobiliária é expressão do descaso pelo lugar de origem, para muitas pessoas que vivem no espaço urbano.

Nesse sentido, é necessário salientar a expressão cultural daqueles que vivem no campo, para se construir uma tese enfocada na relação entre o rural e o urbano, verificando um setor que normalmente é deixado de lado por diversos pesquisadores no Brasil e no mundo, mas que deveria compor os estudos de enfoques econômicos, políticos, sociais e ambientais.

A cultura social é construída de acordo com as características de formação do espaço, formando a base material e imaterial da estrutura cultural, base para a formação territorial das relações sociais no espaço. Porém, é evidente que tal construção se modifica ao longo dos tempos, e a formação cultural regional também se modifica com tais movimentos. 


\section{DIVERS(a)!}

Um dos principais fatores sociais e culturais na formação desse espaço são os processos migratórios. De acordo com Durham (2004), o fato dos imigrantes serem provenientes de áreas de economia tradicional, e muitas vezes trabalharem como colonos para um fazendeiro, tornam o equipamento cultural um tanto quanto fechada e característica da subsistência.

A mudança de hábitos e de local de vida, de afazeres, de conduta, na construção de uma nova etapa de suas vidas, adequa sua cultura aos padrões necessários para sobreviverem. Mesmo considerando que os indivíduos participam diferentemente da culturalocal mais ampla, tais padrões são expressos no modo de vida das pessoas, como padrões de comportamento socialmente transmitidos, que servem para adaptar as comunidades humanas em suas necessidades biológicas. Tais modos de vida, de acordo com Larraia (2005), são expressões de novas técnicas e modo de organização econômica, criação de padrões de se estabelecer e conviver em um local como agrupamento social, além de sua organização política, religiosa, suas crenças, e até mesmo suas casas e hábitos, se constituindo em uma constante dinâmica, mas com uma raiz pautada em seus antepassados e na construção de sua vida.

Diversos grupos se organizavam numa sociedade relativamente autônoma, e se fundamentavam numa economia e relações de base familiar. Dessa maneira, de acordo com Durham (2004, p. 145) "[...] a ocorrência das famílias extensas, tão comuns em comunidades campesinas, parece estar associada à necessidade de conservação de propriedades economicamente suficientes, quando o solo é valioso ou escasso." Isso aumenta o trabalho sobre a terra, e evita seu desmembramento entre os herdeiros. A relação era totalmente paternal, onde os pais tomavam as principais decisões, e havia atitudes de respeito dos filhos e da esposa em relação ao pai. Os filhos permanecem subordinados ao pai até a idade adulta, ou mais precisamente até o casamento, quando passa a procurar condições para sua nova família.

São os filhos homens, junto com o pai, os responsáveis pela produção do grupo em campo, numa clara divisão de tarefas. Às mulheres, cabem as tarefas domésticas, como cuidar da casa, dos elementos não-produtivos da família (velhos, crianças, doentes), preparar os alimentos, as roupas, cuidar do quintal (aves, porcos), da horta etc. Embora pareça uma prática machista, o trabalho no campo necessita de força, e a maioria das famílias campesinas possuem essa 


\section{DIVERS(a)!}

característica bem marcante ainda hoje, mas principalmente quando os primeiros pioneiros consolidaram a formação regional de uma localidade, formando sua cultura em meio a atividades econômicas e políticas, muitas vezes relacionando-as.

Várias são as visões e interpretações ao longo da história sobre a cultura e sua dinâmica. De acordo com Sauer (2003, p. 23), "O desenvolvimento da geografia cultural procede necessariamente da reconstrução das sucessivas culturas de uma área, começando pela cultura original e continuando até o presente." Neste aspecto, a proposta de Sauer prevê a análise histórica do local, de acordo com o aproveitamento humano da terra, ou seja, nas marcas explícitas dos registros visíveis do homem sobre o território, considerando suas moradias, suas atividades rurais, seus sistemas de produção e de vida expressos no território.

O método utilizado por Sauer (2003) é evolutivo, histórico, e caracteriza a geografia cultural como a análise documental e visual de uma área, desde sua ocupação até a contemporaneidade, sendo apenas válida até onde as documentações comprobatórias possam validar as diferentes sucessões culturais que ocorreram em uma determinada área, sendo exterior aos indivíduos de um determinado grupo social, ou pela memória viva das pessoas e da história repassada e contada.

Já para Wagner e Mikesell (2003), que seguem a mesma linha de pensamento de Sauer, a geografia cultural deve estar ligada à Terra, principalmente aqueles produzidos e modificados pelo homem. Consideram a geografia cultural como a junção de cinco temas implícitos: cultura, área cultural, paisagem cultural, história da cultura e ecologia cultural. "A cultura resulta da capacidade de os seres humanos se comunicarem entre si por meio de símbolos" (WAGNER; MIKESELL, 2003, p. 28), desde as ações de pessoas mais experientes em um grupo, os objetos feitos pelo homem, até a língua e as linguagens.

Seguindo o mesmo sentido exposto pela escola americana de Berkeley de Sauer, que perdurou de 1925 a 1975, Wagner e Mikesell (2003) completam seu pensamento expondo que o geógrafo cultural não tem como preocupação as explicações do funcionamento interno da cultura, como o comportamento humano individual ou em grupo, mas tem como objetivo a explicação das modificações que estes realizam na superfície da terra, verificando a potencialidade e condições técnicas das comunidades em modificar seus habitats, inclusive sobre os impactos ambientais oriundos dessas ações.

Inúmeras críticas foram construídas sobre os geógrafos sauerianos. Uma das principais indagações foram apontadas no sentido de haver uma homogeneidade cultural, uma falta de críticas aos assuntos relacionados ao comportamento humano, atitudes, 


\section{DIVERS(a)!}

crenças, entre outros. De acordo com Duncan (2003, p. 89), a separação do indivíduo da cultura é um erro ontológico, assim como os adeptos da teoria supraorgânica. Quando a cultura é definida como uma entidade supraorgânica ela não é "[...] apenas inconveniente como uma variável explanatória, mas também se torna um obstáculo para a explicação por ocultar diversas relações sociais, econômicas e políticas problemáticas."

Também com uma visão crítica à geografia cultural de Sauer, mas com uma proposta materialista dialética, Cosgrove $(2003$, p. 103) analisa a geografia cultural com o objetivo de "[...] apreender e compreender essa dimensão da interação humana com a natureza e seu papel na ordenação do espaço", baseando-se na apropriação simbólica do mundo a partir da produção de seus estilos de vida, criando paisagens e lugares específicos no espaço, além da produção e uso dos recursos naturais em favor dos homens.

A geografia atual considera a cultura como uma forma de análise central para compreender o mundo vivido por grupos humanos. Para Cosgrove (2003, p. 104)

Contudo, mesmo no uso contemporâneo, "cultura" serve para unir os aspectos fundamentais do ser social: (1) trabalho, a interação direta dos seres humanos com a natureza na produção (como "agricultura", "viticultura", "silvicultura"); e (2) consciência, as idéias, valores, crenças e ordem moral nas quais os seres humanos se tornaram cientes de si mesmos como sujeitos capazes de transcender a grosseira materialidade da natureza (como "cultura primitiva", "cultura de classes", "contracultura"). A cultura é o termo central do humanismo, incapaz de definição clara como um conceito objetivo, mensurável, e compreensível apenas através da prática.

Nesse contexto, diante do materialismo histórico, os homens e mulheres têm o poder de escolher sua própria vida, de criar seu próprio caminho através da construção de seu espaço, exercendo sua territorialidade, porém, direcionadas muitas vezes pelas oportunidades criadas no contexto da produção de mercadorias, do trabalho e do lucro. A decisão de procurar um lugar novo para almejar melhores e novas condições de vida, ou plantar um determinado produto, e viver em uma certa sociedade.

Já para Claval (2007), todos os fatores geográficos são culturais. A identidade cultural é resultado de processos históricos de formação e construção do espaço, e por esse motivo, pode ser transformada e modificada em algum momento por algum agente transformador do espaço, sendo que as configurações culturais não

Divers@! Revista Eletrônica Interdisciplinar/Matinhos/Vol.7, n.1, p. $\quad$ /Jan./jun./2014. 72 


\section{DIVERS(a)}

permanecem imutáveis, e a expressão de novas técnicas, políticas e decisões, podem alterar os padrões culturais conhecidos em um lugar, assim como o estudo, novas concepções e relações de vida com novos horizontes e perspectivas.

De acordo com Claval (2007, p. 183), pode-se identificar três elementos essenciais no componente da cultura

1) Na medida em que as culturas não são mais que conjuntos de traços autônomos e independentes uns dos outro, a distância é suficiente para explicar os fatos de distribuição: a difusão tende a criar tantas áreas e limites quantos forem os centros de inovação. 2) Como as civilizações não utilizam todas os mesmos códigos, seus traços culturais específicos param frequentemente sobre as linhas onde mudam as línguas e os sistemas de signos. 3) Como a construção do eu e o vigor dos sentimentos de identidade tornam impossível a adoção de várias atitudes, crenças e hábitos, as culturas podem coabitar nos mesmos lugares, interpenetrarem-se e cruzarem-se sem perder suas especificidades.

A análise de Claval (2007) inter-relaciona estudos sobre a gênese e as interpretações culturais na geografia, analisando posteriormente a cultura, a vida social e o domínio do espaço, o meio e a paisagem, e a geo-história das culturas, considerando que a cultura é comum a diversas áreas das ciências, e que a geografia tem o papel de demonstrar que a cultura possui um papel de mediação entre os homens e a natureza, como herança construída por símbolos, dando condições para que os indivíduos ou grupos protejam sua história, através da memória e das construções de identidade local e grupal.

\section{Modo de vida rural: buscando uma interpretação na relação com o urbano}

O território se apresenta como lugar de representações e relações sociais e culturais em um determinado espaço, seja ele contínuo ou descontínuo. O território contínuo, como expressão da produção neste espaço, pode, enquanto formação material ou imaterial, se (re)territorializar em outros lugares através da sociedade.

Divers@! Revista Eletrônica Interdisciplinar/Matinhos/Vol.7, n.1, p. /Jan./jun./2014. 


\section{DIVERS(a)!}

A natureza se transforma sem a intervenção do homem, em seu ciclo natural, com diversas redes de interação biótica entre as espécies. Com a intervenção humana, o impacto na natureza é uma consequência, pois o simples fato do homem viver e necessitar dos recursos existentes no planeta para sua permanência, mesmo em tempos remotos, traz impactos consideráveis no meio. Com a natural interferência humana na construção dos espaços, tais espaços foram transformados em seus próprios espaços (transformação da natureza em meio rural, ou segunda natureza), ou foram recriados em outros espaços (a urbanização).

Com os impactos oriundos da natureza humana, de seu padrão sócio econômico e cultural, a natureza também se torna cultural, já que é neste espaço que o homem demarca suas ações, modificando objetos, criando símbolos, e utilizando suas formas. Na transformação da natureza em espaço rural (onde muitas vezes estes espaços são os mesmos), no qual o homem domestica animais e plantações para seu viver, o rural se torna o espaço da cultura do homem, e suas relações são determinadas por diversos fatores advindos desse próprio rural, ou na contemporaneidade, provindo de áreas urbanas.

O rural é a natureza modificada, assim como o urbano também o é. O rural simboliza a primeira área de vivência do homem, de sua consolidação histórica enquanto ser social e econômico. O urbano é símbolo de uma cultura integrada, típica de uma necessidade humana em viver em conjunto, de se defender, e posteriormente de gerar a mercadoria. Atualmente, tais defesas devem se basear no próprio homem, já que o maior símbolo de tais mudanças é o próprio, não pela essência humana, mas pelo caminho de forma de produção que a humanidade, ou parte dela escolheu, ou que foram impostas a eles, como o capitalismo. Isso não significa que no socialismo, exista uma relação mais harmoniosa do homem com o espaço transformado, mas que tais relações são diferenciadas e pensadas de forma mais igualitária, mesmo que isso não ocorra sempre.

A interferência do homem na natureza é muito maior quando a transformação ocorrida se expressa no espaço urbano, pois o urbano é símbolo de multiculturalismo, de ideias, de transformações, e em contrapartida, cada vez menos de uma natureza, não que este urbano não seja natureza. Já no meio rural, tais interferências ocorrem baseadas na transformação do lugar, porém, não há 


\section{DIVERS(a)!}

aglomerações humanas devido ao espaço mais amplo, às necessidades (culturais) de quem vive nesta área, no uso do solo e dos recursos. O impacto também existe em relação à natureza, mas a valoração deste é menor se for relacionado com o meio urbano, embora as atividades de monocultura, degradação do solo e uso de agrotóxicos aprofunda essa degradação horizontalmente e também verticalmente.

É inevitável que existam diferenças entre os espaços rural e urbano na atualidade, mas na construção da paisagem atual, os dois espaços já foram os mesmos, principalmente em tempos onde as primeiras civilizações começaram a se aglomerar, e se isolar da natureza que não havia sido transformada, ou utilizada de maneira não periódica, como para a caça, pesca, o extrativismo, entre outros. Só cabe a análise da relação entre o rural e o urbano, se o compreendermos na relação constante de conflitos, desigualdades sociais e regionais, assim como o uso diferenciado de cada espaço no contexto da produção do modo de produção capitalista.

O rural e o urbano começaram a se diferenciar quando o uso dos espaços foi se tornando específico, dividido pelo trabalho, conforme as teorias de desenvolvimento desigual e combinado de Trotsky, e revisados e remodelados por Smith e Harvey. O rural passa a se caracterizar pelo espaço de trabalhos ligados à terra, aos alimentos, às criações e explorações, enquanto o urbano começa a se formar pelas atividades ligadas ao comercio, pela proximidade das pessoas, e tais aspectos transpareceram a necessidade do homem em criar infraestrutura para viver, transformando cada vez mais a natureza. A própria aglomeração de pessoas traz maiores danos, sejam eles pelo uso dos espaços, ou pelos dejetos oriundos da atividade social.

Com o avanço das técnicas e tecnologias, o uso dos espaços culturais começou a se modificar mais intensamente nos territórios. A necessidade da exportação de produtos primários, fez com que o meio rural passasse a ser utilizado em larga escala, baseado em produção monocultora. A natureza passou a ser mais degradada no campo do que nas cidades em extensão, pois mais produção significaria mais áreas para se plantar, além da necessidade de materia-prima como o ferro, manganês, bauxita, entre outros utilizados em grande quantidade nas cidades. Já nos centros urbanos, a mudança se relaciona com a intensidade da 


\section{DIVERS(a)!}

degradação, pois muitas fábrica e empresas processadoras utilizam os recursos da natureza de forma irracional, e joga seus resíduos na própria natureza. Tais culturas são na atualidade, totalmente distintas, pois há espaços dentro desses espaços onde o que foi descrito não ocorre, como áreas deprimidas e típicas de moradores menos desprovidos de recursos.

Quando ocorre uma análise das características dos espaços rural e urbano, estabelece-se uma leitura de um fato rural ou fato urbano, de maneira fragmentada no território, já que a leitura a partir da paisagem oferece parâmetros culturais intra, inter e extraorgânicos de um espaço construído. O mundo rural apresenta características históricas bem particulares e precisas, que foram perdendo suas especificidades principalmente com o avanço da tecnologia e dos aparatos expressos na modernidade, e que de acordo com Capra (1982), vai se esvaziando e se perdendo do tempo, principalmente com a falta de resgate da memória coletiva do meio rural, em detrimento do tempo rápido encontrado no meio urbano, isto é, na maioria dos meios urbanos, já que em alguns lugares o tempo permanece lento em relação ao tempo das cidades, acompanhando o ritmo de vida e característica do rural local, onde o trabalhador tem como relógio o sol, as semanas e os meses, já que seu trabalho se inicia ao nascer e termina ao se pôr, que tem como premissa a vida das plantações em diversas escalas em cada tempo específico.

O debate acerca da relação entre rural e urbano, enfatizando a cultura rural e o avanço da modernização, tipicamente urbana, no mundo rural é extremamente complexa e abrangente, sendo praticamente impossível analisar todos os aspectos culturais existentes nessa relação, muitas vezes antagônicas, e outras complementares. Considerando a dualidade existente entre cidade e o meio rural, Lima (2005, p. 56) esclarece que

Inversamente ao que ocorre na cidade, no espaço rural brasileiro o povoamento é mais rarefeito e disperso em relação ao centro municipal. O "rural" supõe uma nova definição: a dispersão de sua população, não havendo presença do poder público no seu espaço, não há também prestação de bens e serviços que estão concentrados na área urbana. Assim, o "rural" encontra-se atrelado à cidade, como problema espacial dependente política, econômica e socialmente. 


\section{DIVERS(a)!}

As características básicas da relação entre campo e cidade, estão na transformação realizada entre os moradores de cada espaço, capazes de construílos através de um conjunto de ações em objetos específicos, engendrados numa lógica do capital que, na maioria das vezes, direciona suas atitudes conforme as dificuldades apresentadas.

De acordo com Queiroz (1992), o rural é sinônimo de natureza, e a atividade agrícola é uma modificadora dessa natureza. Considerando a agricultura como prática cultural, existe uma oposição entre natureza e cultura, embora haja uma cultura rural. O rural é definido como um espaço de ausências, da natureza, de uma população reduzida, da baixa atividade econômica, se comparado com o urbano, mesmo em regiões onde a prática do agronegócio é mais evidente.

Encontra-se em Macfarlane (1989) e Thomas (2010) uma explicação para a possível origem do antiurbanismo. Como exemplo, toma-se a Inglaterra do século XVIII, considerada a mais urbanizada do mundo no período, e se estendeu aos demais espaços do planeta. O antiurbanismo surgiu a partir das condições insalubres originadas a partir da superpopulação concentrada em cidades, tornando precária a qualidade de vida de seus moradores, dentre elas a qualidade do ar, o barulho intenso, o stress, dentre outros problemas. Nesse sentido, os moradores das cidades ansiavam pela vida rural, ou por cidades menores, de fácil deslocamento.

O campo representava uma maior proximidade com a natureza, a tranquilidade, as plantas e os animais, sem deixar de lado os recursos das cidades, principalmente referentes à comodidade. Essa busca traz na construção da identidade local, uma maior aproximação com a religiosidade. Para Thomas (2010, p. 297), "Deus fizera o campo, o homem a cidade." A vida próxima à natureza era tida como uma aproximação divina, longe das impurezas existentes nas cidades, sobretudo o consumismo, o capitalismo, os desejos, dentre outras peculiaridades.

Tais valores estão no imaginário do homem, no poder simbólico (BOURDIEU, 2000) da economia das cidades e na nostalgia do campo, por ser criado de acordo com sua cultura. O que faz as pessoas se aproximarem do campo, é a representação existente nesse espaço, no contexto de uma busca por um convívio com a natureza, e principalmente o prazer de viver bem, contraposto aos bens materiais, e sem a necessidade de se buscar a sobrevivência, pois se aproveitam do 


\section{DIVERS(a)!}

contexto tecnológico existente nas cidades. Essa formação de um novo padrão de pessoas se denomina neorural (GIULIANI, 1990), num padrão corroborado por Thomas (2010) e Macfarlane (1987).

\section{CONSIDERAÇÕES FINAIS}

Dessa forma, a análise da dicotomia entre rural e urbano é consignada neste trabalho de duas formas: a primeira, marcada pelo uso e construção do espaço engendrada em necessidades de sobrevivência, e fatores externos ao lugar, como políticas públicas de desenvolvimento rural, expressas na paisagem. Neste contexto, tem-se o rural caracterizado como expressão da paisagem e ao uso específico de atividades agrícolas, não-agrícolas, infraestrutura, presença de recursos naturais, em quantidade muito superior à encontrada, em vários casos, no urbano. A segunda forma se refere ao espaço rural como modo de vida, como expressão cultural de pessoas que vivem e convivem nesse meio, e até mesmo com relação ao avanço tecnológico, que modifica os padrões culturais dos moradores desse espaço.

Muitos moradores das cidades, principalmente as metrópoles ou grandes centros, procuram se deslocar para o campo em busca de uma maior ligação com a natureza, e principalmente para fugirem dos problemas e dificuldades encontradas nas cidades, como o trânsito, a poluição e a insegurança, morando em condomínios fechados de luxo ou chácaras e fazendas nas proximidades dos centros urbanos, através de uma visão mítica do rural (SILVA, 2000). Até mesmo aqueles que possuem condições sócio econômica mais frágil, usam o espaço rural pela proximidade com a natureza, procurando a utilização de espaços públicos para se utilizarem em seus deslocamentos.

Porém, poucos mudam seus costumes e hábitos de vida, usufruindo das ruralidades sem modificar sua maneira de viver. Sua ligação ainda provém da cidade, mas momentos de sua vida e de seu ócio ocorrem no campo, e estes não querem, de forma alguma, que este campo se torne cidade, mas que apenas tenham acesso às comodidades oferecidas pelo meio urbano, como a tecnologia 


\section{DIVERS(a)!}

(celular, TV, internet, computador etc), produtos industrializados, equipamentos, entre vários outros.

O mesmo ocorre com o morador do campo, que aproveita a cidade para passear, fazer compras e se divertir com a família, além de visitar filhos ou parentes, dentro das condições econômicas num contexto consumista da sociedade capitalista atual. Estes permanecem com suas características e costumes, mesmo estando nas cidades. Isso reflete que a maioria não se mudaria para a cidade, mesmo sendo esta de pequeno porte, a não ser que surgisse uma boa oportunidade de trabalho, mas os mesmos não a procuram.

A proposta apresentada, apesar de não expressar uma pesquisa de caso específico, faz parte das discussões a respeito do trabalho empírico, construído em conjunto com a teoria apresentada, e pode ser melhor compreendida no trabalho defendido pelo autor. Evidentemente que não pretendemos aqui esgotar o assunto, mas proporcionar ao leitor um direcionamento possível na compreensão da relação entre o campo e a cidade, demonstrando a necessidade de utilização da geografia cultural para compreensão dos fenômenos criados e recriados em um determinado espaço, diante da diversidade exposta na particularidade de cada lugar.

\section{REFERÊNCIAS}

BOURDIEU, Pierre. O poder simbólico. 3. Ed. Rio de Janeiro: Bertrand Brasil, 2000

CAPRA, Fritjof. O ponto de mutação. São Paulo: Cultrix, 1982.

CLAVAL, Paul. A geografia cultural. 3. Ed. Florianópolis: UFSC, 2007.

COSGROVE, Denis E. Em direção a uma geografia cultural radical: problemas da teoria. In: CORREAA, Roberto L. \& ROZENDAL, Z. (Orgs.) Introdução à geografia cultural. Rio de Janeiro: Bertrand Brasil, 2003. P. 103-134.

DUNCAN, James S. O supra-orgânico na geografia cultural americana. In: CORREA, Roberto L. \& ROZENDAL, Z. (Orgs.) Introdução à geografia cultural. Rio de Janeiro: Bertrand Brasil, 2003. P. 63-102.

Divers@! Revista Eletrônica Interdisciplinar/Matinhos/Vol.7, n.1, p. /Jan./jun./2014. 


\section{DIVERS(a)!}

DURHAM, Eunice R. A dinâmica da cultura: ensaios de antropologia. São Paulo: Cosac Naify, 2004.

GIULIANI, G. M. Neo-ruralismo: o novo estilo dos velhos modelos. Revista brasileira de ciências sociais. N. 14, p. 59-67, out. 1990.

LARRAIA, Roque. de B. Cultura: um conceito antropológico. 18.ed. Rio de Janeiro : Jorge Zahar, 2005.

LIMA, E. N. Novas ruralidades, novas identidades. Onde? In: MOREIRA, R. J. (org.) Identidades sociais: ruralidades no Brasil contemporâneo. Rio de Janeiro: DP\&A, 2005. P. 41-64.

MACFARLANE, Alan. A cultura do capitalismo. Rio de Janeiro: Jorge Zahar, 1989.

QUEIROZ, M. I. P. Carnaval brasileiro: o vivido e o mito. São Paulo: Brasiliense, 1992.

THOMAS, K. O homem e o mundo natural. Mudanças de atitude em relação às plantas e os animais (1500-1800). São Paulo: Companhia das Letras, 2010.

SAUER, C. Geografia cultural. In: CORRÊA, Roberto L. \& ROZENDAL, Z. (Orgs.) Introdução à geografia cultural. Rio de Janeiro: Bertrand Brasil, 2003. P. 19-26.

SILVA, Gislene. 0 imaginário rural do leitor urbano: o sonho mítico da casa no campo. São Paulo: PUC, 2000. Tese de doutorado em Ciências Sociais/Antropologia.

WAGNER, P. L.; MIKESELL, M. W. Os temas da geografia cultural. In: CORRÊA, Roberto L. \& ROZENDAL, Z. (Orgs.) Introdução à geografia cultural. Rio de Janeiro: Bertrand Brasil, 2003. P. 27-61. 